\title{
Porous media approach for RANS simulation of compound open-channel flows with submerged vegetated floodplains
}

\author{
Moisés Brito $^{1} \cdot$ João Fernandes ${ }^{2} \cdot$ João Bento Leal ${ }^{3,4}$
}

Received: 4 September 2015/Accepted: 22 August 2016/Published online: 9 September 2016

(C) Springer Science+Business Media Dordrecht 2016

\begin{abstract}
The main goal of this study is the 3D numerical simulation of river flows with submerged vegetated floodplains. Since, vegetation layers are usually dense and present a large spatial heterogeneity they are here represented as a porous media. Standard semiempirical relations drawn for porous beds packed with non-spherical particles are used to estimate the porous media parameters based on the averaged geometry of the vegetation elements. Thus, eliminating the uncertainty arising from a bulk drag coefficient approach and allowing the use of a coarser mesh. The free flow is described by Reynolds-averaged Navier-Stokes (RANS) equations, whereas the porous media flow is described by the volumetric-average of RANS equations. The volume-of-fluid method and an anisotropic explicit algebraic Reynolds stress model are used for free-surface and turbulence closure, respectively. The simulation approach is validated against results by other authors featuring vegetated flows in horizontal and rectangular open-channel. The computed results show that the time-averaged streamwise velocity and Reynolds shear stress vertical profiles are properly simulated. The validated approach was applied to simulate compound openchannel flows with submerged vegetated floodplains and compared with data obtained in an experimental facility. The results show that the proposed porous media approach is adequate to simulate flows with submerged vegetation on the floodplains.
\end{abstract}

Keywords Compound open-channel · Submerged vegetation · Porous media · EARSM $\cdot$ Mixing-layer

Moisés Brito

moises.brito@tecnico.ulisboa.pt

1 CEris, DECivil, Instituto Superior Técnico, Universidade de Lisboa, Av. Rovisco Pais, 1049-001 Lisbon, Portugal

2 DHA, National Laboratory for Civil Engineering, Av. do Brasil 101, 1700-066 Lisbon, Portugal

3 Faculty of Engineering and Science, University of Adger, Postboks 509, 4898 Grimstad, Norway

4 UNIDEMI, FCT, Universidade Nova de Lisboa, Campus da FCT/UNL, 2829-516 Caparica, Portugal 